\title{
Professores comprometidos: a interação social na orientação de trabalhos de conclusão de curso
}

\author{
ANDRÉA PAVÃO \\ UNIVERSIDADE FEDERAL FLUMINENSE (UFF), RIO DE JANEIRO/RJ, BRASIL \\ HTTPS://ORCID.ORG/OOOO-OOOI-9I2I-7886
}

\section{Introdução}

Este artigo deriva de uma pesquisa mais ampla ${ }^{1}$ cujo objetivo geral é estudar e comparar o papel do vínculo social entre orientadores e estudantes no desenvolvimento do Trabalho de Conclusão de Curso (TCC) de Pedagogia entre uma universidade brasileira e outra espanhola. Neste texto me detenho sobre o caso brasileiro e, mais especificamente, sobre uma única categoria nativa: a dos professores comprometidos ${ }^{2}$.

A escolha desta categoria não é fortuita. Ela já havia aparecido durante o trabalho de campo no Brasil, mas foi na Espanha que ganhou mais relevo, por oposição a uma outra categoria recorrente no contexto espanhol: a dos professores pasotas ${ }^{3}$. Chamou minha atenção o fato de no Brasil não haver uma categoria para os professores que "não ligam para nada", nem na Espanha haver uma para os que se dedicam aos estudantes de forma distintiva, aparentemente de maneira graciosa ou, ao menos, sem nenhum benefício material aparente, além de poder desfrutar da face de professor comprometido, nos

1 Projeto de tese de doutorado em Sociología y Antropología da Facultad de Ciencias Políticas y Sociología da Universidad Complutense, sob orientação da Professora María Isabel Jociles.

2 Agradeço, emocionada, aos pareceristas e à equipe de edição da revista pela leitura meticulosa, contribuições precisas e inteligentes. O resultado final desta versão se afasta muito da versão original apresentada na XIII RAM, em 2019. Pareceristas e equipe de edição atuaram como verdadeiros "orientadores comprometidos". Espero que o resultado desta aposta venha ser vantajoso aos leitores. Mais do que gerar um produto rentável academicamente, a mim, pessoalmente, publicar é uma experiência formativa! "Escrever é um ato de amor, se não o é, não passa de escritura" (Jean Cocteau).

3 Este termo vem da expressão espanhola pasar de todo. Aquele que pasa de todo é um pasota, que não quer saber de nada, que é pouco trabalhador. 
termos de Goffman (1985). Minha primeira hipótese é que tal categoria remeta a um tipo de performance ideal.

Parto do pressuposto de que o domínio da cultura escrita é imprescindível ao exercício pleno da cidadania. Reconheço, ainda, que, em uma sociedade de classes, os modos diferenciais de apropriação da cultura escrita reproduzem relações de poder entre seus usuários e que estes modos particulares de participar de práticas sociais viabilizadas pela escrita têm grande influência nos jogos de inclusão e exclusão social. Além disso, considero que estas habilidades diferenciais não se desenvolvem sem mediação social (Pavão, 2017), uma vez que não são naturais ou inatas. Daí a importância de a escola pública se impor como meio de socialização preferencial da cultura escrita, normalmente restrita às classes médias e altas, ao menos em suas formas mais legitimadas ou escolares.

No Brasil, a distribuição destas aptidões é bastante desigual em função da origem social e geográfica da população. Dados estatísticos divulgados por Louzano (2010) revelam que, entre egressos da Educação Básica, por exemplo, a maioria dos estudantes brasileiros que procurava os cursos de Pedagogia e demais licenciaturas se encontrava na faixa que apresentava os mais baixos níveis de proficiência de leitura e escrita. Paradoxalmente, é sobre este segmento que se depositam as mais altas expectativas na tarefa de superação das desigualdades do país.

Concretamente, espera-se que, uma vez em serviço, estes futuros professores sejam capazes de atuar como mediadores para que seus alunos dos primeiros anos de escolaridade alcancem os melhores níveis de proficiência da leitura e da escrita. Mas o que é oferecido aos futuros professores para que possam exercer esta função? Para que os docentes da Educação Básica possam fazer jus a esta responsabilidade, seria necessário que os estudantes de licenciatura desenvolvessem, nos quatro anos da faculdade, as habilidades de leitura e escrita que não adquiriram de forma satisfatória ao longo dos treze anos de Educação Básica. Isso me parece um desafio desmesurado.

Em pesquisa anterior (Pavão, 2007) sugeri que, entre as diversas situações de ensino-aprendizagem ao longo da faculdade de Pedagogia, a pesquisa e redação de um TCC sob a orientação de um usuário mais experiente, com altas habilidades em leitura e escrita, é uma situação de mediação privilegiada e estratégica, apesar das difíceis condições materiais nas quais costuma ocorrer. Diferentemente das práticas habituais de ensino-aprendizagem que se dão nas disciplinas formais, a orientação de TCC favorece a construção de um estreito laço social e afetivo entre estes atores sociais.

Afinal, é uma das únicas situações, ao longo da formação, na qual o estudante tem um atendimento individual e recebe orientações específicas tanto sobre a leitura (o que ler, como ter acesso a artigos científicos, como interpretar o que se lê, como usar o que se lê), quanto sobre produzir um texto acadêmico autoral (qual vocabulário utilizar, questões de coerência e coesão, etc.) a partir de um tema de seu interesse pessoal, ou seja, que implica o desejo do próprio estudante. Importante reconhecer, entretanto, que o TCC é um dos requisitos para a graduação mais responsável pelo adiamento da conclusão do curso e mesmo de seu abandono (Pavão \& Serrado, 2019) em ambas instituições estudadas.

Neste artigo exploro a natureza da interação que se constrói ao longo deste processo através de análise de material empírico, obtido por meio de entrevistas e observação participante em uma Facul- 
dade de Educação ${ }^{4}$. Busco, assim, compreender os significados de atuar como professor comprometido nesta delicada situação de interação social. Procuro, principalmente, compreender as possíveis razões do improvável trabalho de alguns docentes que, resistindo à lógica produtivista, reconhecem as dificuldades de seus alunos e dedicam parte significativa de seu tempo a esta tarefa pouco valorizada em suas carreiras profissionais.

\section{O campo empírico e as estratégias metodológicas}

O curso brasileiro de Pedagogia estudado é oferecido em uma Universidade Pública Federal de excelência acadêmica que, a partir de agora, chamarei de UPF. O trabalho de campo se deu numa pequena unidade de interior, criada inicialmente com apenas um único curso, o de pedagogia, em 1992. A escolha desta universidade e, em especial, deste curso como locus de investigação, se justifica pelo fato de este ter sido o primeiro curso de Pedagogia no Brasil a adotar o trabalho monográfico de final de curso como pré-requisito para a obtenção do título de licenciatura e por seu currículo inovador ter influenciado as políticas nacionais de formação de professores.

Em maio de 2021, este curso contava com trezentos e quinze estudantes, em sua maioria de outras regiões do Brasil, de origem popular e de camadas médias baixas capazes de arcar com as despesas de seus filhos fora da casa dos pais. Deste universo de estudantes, $75 \%$ têm renda familiar inferior a quatro salários mínimos e cursou toda Educação Básica na rede pública ou em colégios particulares de pouco prestígio. A maioria, quase 70\%, estuda e trabalha (Pavão \& Serrano, 2017). Alguns tiveram tentativas frustradas de ingresso em outros cursos mais valorizados dentro de seu campo de possibilidades que são, ainda assim, de Humanas, como Letras, Serviço Social, e demais licenciaturas que habilitam para atuar no segundo segmento do Ensino Fundamental e Ensino Médio (Pavão, 2007). Neste sentido, reitera-se no curso estudado a tendência identificada por Louzado (2010): para aproximadamente $70 \%$ de todas as matrículas em Pedagogia no Brasil, este curso não era a primeira opção.

$\mathrm{Na}$ UPF, a pesquisa se desenvolveu em dois momentos. O primeiro teve início em 2010, quando meu interesse inicial era conhecer o papel do TCC no currículo original do curso. Nesta fase, foram entrevistados oito professores que atuaram no curso entre 1992 e 2010. Por não serem lotados na unidade de interior, abraçar este projeto lhes exigia um deslocamento semanal significativo. Desde 2006 não havia mais entrada de estudantes por vestibular e, em 2010, quando iniciei o trabalho de campo, poucos professores mantinham a rotina das viagens para a unidade de interior com a finalidade de atender a um número já reduzido de estudantes remanescentes.

Em 2009, no âmbito das políticas de Reestruturação e Expansão das Universidades Federais (Reuni), foram realizados os primeiros concursos para professores com lotação nesta unidade. No ano seguinte, novas turmas se formaram através do Sistema de Seleção Unificada (SISU) e, em 2016, decidi fazer um estudo comparado entre o currículo experimental e o que veio a substitui-lo depois da reforma curricular em 2010, para atender à nova legislação. Nesta fase, foram entrevistados doze orientadores.

4 Apesar de o trabalho de campo ter sido realizado junto a cursos de Pedagogia, acredito que a discussão de seus dados pode gerar rendimento também para os demais espaços de formação de professores, além das Ciências Sociais em geral. 
O trabalho de campo na Espanha, por sua vez, se deu entre 2017 e 2018 e será utilizado, ainda que de forma incidental, como parâmetro nos primeiros passos de um estudo comparativo. A Universidade Espanhola, a qual passarei a me referir por UEP, também é pública e está localizada no interior. Ao longo deste texto, me referirei ao curso correspondente à primeira etapa da pesquisa por Curso Experimental, à segunda como Curso do Reuni e à terceira, na Espanha, por Curso Espanhol.

No Brasil, em ambas as fases, a pesquisa se desenvolveu através da observação participante. Pude acompanhar diversas situações do cotidiano institucional: reuniões pedagógicas, de colegiado de curso e departamentais; reuniões e cerimônias de formatura; interações em salas de aula; além de algumas reuniões de orientação e espaços de convivência social. Também observei a relação de orientadores e seus orientandos em diversas edições da Semana Acadêmica da UPF, na qual os trabalhos finais são apresentados para um prêmio 5 . Na UPF não há defesa de TCC.

Importante informar ao leitor sobre a posição da pesquisadora no campo empírico. Trata-se de uma etnografia nativa, ao menos em sua fase brasileira, uma vez que integro o corpo docente do curso estudado da UPF desde $2009^{6}$. Em virtude desta posição peculiar, também pude exercitar meu lugar de escuta entre estudantes, seja através de entrevistas, seja através de encontros informais e demais espaços de observação participante no cotidiano deste campus de interior. Os estudantes são atores muito importantes para compreender o sistema de classificação dos orientadores, evidentemente.

Por outro lado, como professora desta unidade, a convivência com outros docentes era muito intensa e de grande intimidade, já que morávamos em uma "república de professores" e as declarações espontâneas extrapolavam muitas vezes as regras de convivência nos espaços formais. Momentos importantes de conversas se davam também nas quase três horas de viagem de ida ou de volta ao trabalho, quando trocávamos experiências sobre o desafio de orientar estudantes de graduação.

Além deste rico e intenso trabalho, totalmente imersa na instituição, desenvolvi entrevistas semiestruturadas, com um roteiro construído a partir dos objetivos específicos da investigação. A maioria destes encontros não durou menos de duas horas, já que os interlocutores tinham muito interesse em falar de sua experiência como orientadores, pouco consciente para eles até então. A maioria comentou, de uma forma ou de outra, o quão interessante era a entrevista para compreender seu saber fazer (Bourdieu, 1998). E, embora cada professor só tenha sido entrevistado formalmente uma vez, pelo convívio estreito e diário, as informações que obtive deles, de forma espontânea e em situações variadas, foram muito valiosas.

Não poderia deixar de mencionar a convivência estreita com a secretária do curso, quem representou para esta pesquisa o que Doc representou para Foote White (1980): uma "informante" privilegiada. Esta técnica administrativa é considerada a memória viva do curso e trabalha na unidade desde sua fundação, em 1992, até o momento atual. É dela o primeiro registro que tenho do termo nativo professor comprometido, ainda na fase anterior à das entrevistas, evidenciando que esta qualificação cor-

$5 \mathrm{Na}$ UEP não tive acesso às reuniões institucionais, mas foi onde me foi mais fácil o acesso às reuniões de orientação. Também observei as defesas de TCC e tive acesso a uma cerimônia de formatura.

6 Para maior acercamento ao debate acerca da relação de familiaridade e estranhamento em função da inserção do pesquisador com o campo sugiro o já clássico de Gilberto Velho (1978).

7 Moradia alugada por vários professores que trabalham na UPF e mantêm sua residência fixa em outros municípios. 
respondia a uma distinção muito valorizada naquele curso. O termo também apareceu na conversa que tive com uma jovem socióloga, de sólida formação, com mestrado em Ciências Sociais, que trabalhava à época em institutos de pesquisa particulares como freelancer. Para complementar sua renda, em seus próprios termos, dizia atuar no submundo acadêmico, cobrando para orientar e revisar trabalhos de estudantes, inclusive da UPF. Desde este ponto de vista, portanto, seus comentários têm bastante interesse para compreendermos, por oposição, o papel de um orientador comprometido.

Segundo esta profissional, os estudantes que a procuravam tinham as seguintes reclamações: "os orientadores não respondiam"; "nunca tinham tempo para atender presencialmente os alunos"; "os alunos sentiam medo de levar bronca por apresentarem suas dúvidas estúpidas a um PhD"; "os professores apenas advertiam que o texto estava ruim, sem indicar como melhorá-lo"; "não indicavam bibliografia e esperavam que os alunos tivessem uma autonomia que eles realmente não tinham". Os clientes potenciais da socióloga-que-trabalhava-no-submundo-acadêmico, portanto, são os orientandos de professores que, na Espanha, são conhecidos como pasotas, embora, como já comentei, não tenha observado um termo próprio para designar este perfil de professor no Brasil, o que não significa que este perfil não exista.

No presente trabalho, portanto, decidi concentrar a análise sobre seis encontros, como prefiro me referir às situações de interação comumente chamadas de entrevistas ${ }^{8}$. De um total de vinte encontros, oito do Curso Experimental e doze do Curso do Reuni, selecionei três docentes que gozam do status de professor comprometido em seus respectivos cursos.

Ao longo do texto, utilizo expressões que representam um traço de sua singularidade como professor orientador e, ao mesmo tempo, preservam sua identidade - conforme acordado no termo de livre consentimento esclarecido, assinado por todos. Esta solução foi importada da literatura de autores como José Saramago (2001), em seu Ensaio sobre a Cegueira, e André Sant'Anna (1999), em seu Sexo. Ambos os autores, para se referirem aos personagens, se utilizam do dispositivo de substituir o nome próprio por um predicado. Esta operação me pareceu útil ao trabalho etnográfico na medida em que coloca o acento nas qualidades relacionais e não nas substantivas, se afastando, de certa maneira, do essencialismo e se aproximando da ideia goffmaniana de "subjetividade contingente", como produto da própria interação social.

Seria possível dizer que se trata de uma operação de despersonalização. Não se trata de uma subjetividade estável, mas de qualidades provisórias e circunstanciais atribuídas por mim como autora e segundo meus interesses analíticos. Como diz Eduardo Coutinho, praticante confesso de uma "antropologia selvagem" (Frochtengarten, 2009), os entrevistados de seus documentários se convertem em personagens na medida em que são deslocados de seu mundo particular e incluídos em uma montagem editada pelo diretor que, apesar de ter atuado com cinema documental, reconhece a dimensão

8 Enquanto na primeira fase da pesquisa, no Brasil, lancei mão do método tradicional de registro sonoro com posterior transcrição, na segunda fase, tanto no Brasil quanto na Espanha, a partir de uma reflexão teórico-metodológica (Pavão, 2018), decidi-me por fazer registro audiovisual das entrevistas. O ponto de partida desta opção foi o fato de as situações de entrevistas serem, elas mesmas, interações sociais nas quais se constrói (ou não, nos casos das entrevistas fracassadas, porque sempre acontece, afinal) um laço e o recurso audiovisual oferece um material muito mais rico de análise (Frochtengarten, 2009). Além de poder analisar o diálogo transcrito destas conversas, foi possível rever a cena de interação destes encontros e a qualidade do laço que se estabeleceu como informação extra sobre a comunicação não verbal. 
ficcional de seu trabalho. Acredito, seguindo a trilha de Geertz (2005), que o mesmo se dá no trabalho etnográfico: no momento em que interpreto o campo empírico a partir de minha própria singularidade como pesquisadora, e ilumino os depoimentos dos atores sociais, recortando aqui e ali, editando, segundo meus interesses de pesquisa, produzo personagens de uma espécie de obra que não deixa de ser uma criação e, portanto, tem uma dimensão ficcional. Passo agora a explorar esta categoria emic.

\section{Os professores comprometidos e os pasotas}

Antes de tudo, é preciso advertir o leitor: há uma elipse na expressão professor comprometido. A partir do trabalho de campo, subentende-se que o termo completo seria professor comprometido com a causa. O substantivo causa oculta mais um termo. À qual causa o professor estaria comprometido? Nos cursos de Pedagogia, especificamente, se supõe que o comprometimento diga respeito à causa político-humanitária de ajudar os menos favorecidos a realizar algum tipo de mobilidade social, afastando-se da pobreza e falta de horizontes, condição da maioria destes estudantes. Comprometimento, neste caso, também se aproxima de engajamento político. É preciso dar ênfase ao termo ajudar que traz a ideia de que a disposição de ser comprometido com a causa seja um plus, algo a mais que não se esperaria normalmente e, sobretudo, que não faz parte do conjunto de obrigações profissionais de um professor universitário. Que ganhos implicaria este a mais?

Professor comprometido é termo que aparece, sobretudo, na fala dos estudantes ao se referirem aos professores, mas também entre os próprios docentes, em reuniões departamentais, por exemplo, ao se referirem a colegas. A principal característica do orientador comprometido parece ser a de manter uma boa relação de correspondência. Como nos casos de intercâmbio de cartas, ou em uma conversa, nos quais se pode inferir o nível de comprometimento dos atores envolvidos seja pela frequência, prontidão e qualidade de resposta aos estímulos, na relação de orientação um indicador muito valorizado pelos estudantes é a capacidade de os orientadores responderem prontamente às demandas discentes. A socióloga-que-trabalhava-no-submundo-acadêmico comentou que uma de suas clientes, estudante da UPF, que já havia passado por vários orientadores com os quais não conseguia avançar no desenvolvimento de seu TCC, lhe havia comentado: "minha orientadora respondeu!" ao que minha informante concluiu: "agora vai!".

A categoria se relaciona principalmente com a dedicação de tempo à atividade de orientação, sendo valorizado pelos estudantes se o professor corrige "tim-tim por tim-tim", se separa material bibliográfico para seus orientandos ou se indica bibliografia. Gestos de aproximação afetiva, como ser empático e compreensível com os problemas pessoais, pelos quais costumam passar os estudantes durante o processo, são um traço marcante da maneira "comprometida" de lidar com a tarefa de orientação. Alguns alunos dirão que o professor comprometido é aquele que, de alguma forma, acolhe o aluno, respeita sua singularidade, reconhece as dificuldades do processo e ajuda o máximo que pode, estimulando-o a prosseguir e finalizar sua monografia de forma minimamente satisfatória.

Nas entrevistas com os professores orientadores, o comprometimento com a causa costuma aparecer acompanhado de uma sensação de que "faço mais do que deveria”. Perguntados se sentem re- 
compensados de alguma forma alternativa, costumam dizer, com satisfação, que gostam simplesmente de ajudar os estudantes, colocando acento na gratuidade. Alguns relatam casos nos quais, ao final do processo, recebem dos alunos singelos presentes em sinal de reconhecimento. Esta gratidão também é comumente registrada na seção de agradecimentos na redação final do TCC bem como nas cerimônias de formatura, nas quais os professores comprometidos costumam ser homenageados. Apesar do amoroso reconhecimento dos estudantes, alguns professores expressam uma sensação de estar "enxugando gelo", mas, mesmo assim, não podem evitar a dedicação que reconhecem "excessiva”. Não raro, se desenvolve um laço para além da relação de orientação, através de uma forma de amizade que se prolonga no tempo e pela qual se permite saber de alguns feitos biográficos marcantes do ex-orientando: se fez concurso, se conseguiu vaga na rede púbica de ensino, se entrou para o mestrado ou se casou e teve filhos.

Embora possa ser expresso por outros significantes que não exatamente o de orientador comprometido, e esta mesma categoria possa admitir nuances singulares dependendo do ator entrevistado, este conjunto de disposições citadas definem suficientemente bem este perfil de orientador no sistema classificatório nativo - o qual é mais ou menos compartilhado tanto por professores quanto por estudantes e até por funcionários. Em trabalho anterior (Pavão, 2011:204), as principais categorias nativas pelas quais os orientadores são procurados pelos estudantes foram assim descritas:

A pesquisa de campo indica que a escolha do orientador é motivada por razões diversas tais como: nivel de exigência (em geral, são preferíveis os menos exigentes), capacidade de colaboração (facilitar acesso a material bibliográfico, e até redigir trechos da monografia, revisar, digitar e formatar os trabalhos); afinidade afetiva; disponibilidade de tempo para dedicação à orientação e, ainda, coincidência de horários disponiveis entre as partes.

De acordo com esta classificação, os professores comprometidos são os que congregam a maioria das qualidades citadas, em especial, oferecer maior capacidade de colaborar, podendo ser um professor comprometido muito ou nada exigente. No Brasil, o professor comprometido parece ser o excepcional, enquanto na Espanha, o pasota parece ser mais inesperado. Como a categoria brasileira de professor comprometido foi construída em oposição à espanhola profesor pasota, me pareceu necessário incluir na análise deste artigo o único exemplar ao qual tive acesso, na Espanha, de orientador que não faz mais do que o estritamente necessário, sendo acusado de pasota por alguns dos estudantes escutados.

Por razões evidentes, os professores que são assim representados socialmente não estão muito disponíveis a colaborar com a pesquisa. Além disso, por se tratar de uma "característica diferencial desvantajosa" (Goffman, 1980), os pasotas não assumem facilmente este estigma. Resumindo, o professor comprometido é aquele que faz laço, que se compromete com o aluno e com a causa, por oposição ao pasota que não responde, não corresponde, não atende à demanda do estudante, não se preocupa, não ajuda e não tem, em última instância, compromisso com a causa.

De um modo ou de outro, cabe a pergunta: Quais são as motivações que levam estes professores a se dedicarem de forma tão intensa a uma tarefa tão "mal paga", ou seja, pouco valorizada na carreira acadêmica? Que tipo de recompensas buscariam, então? Que peso, em suas múltiplas atividades como professor universitário, é atribuído à tarefa de orientar TCC? Por que razão, com tanta sobrecarga de 
trabalho (entre as tarefas obrigatórias de docência, pesquisa, extensão e gestão), com estudantes com importantes dificuldades iniciais, ainda assim, alguns professores se esforçam tanto para ajudar seus alunos a superar seus problemas em relação à leitura e à escrita?

\section{Das condições materiais do trabalho de orientação}

Um ponto de consenso entre os professores entrevistados no Brasil é a dificuldade dos estudantes tanto para redigir quanto para ler e interpretar a bibliografia sugerida para fundamentar o TCC. Sua falta de autonomia nestas tarefas centrais acaba sendo uma carga extra aos professores que, segundo seus relatos, não consideram que o trabalho de orientação deveria incluir o desenvolvimento de aptidões tão básicas como interpretar e redigir textos. Eles chamam bastante atenção para o fato de o problema não estar relacionado à falta de familiaridade com a escrita acadêmica, especificamente, o que seria esperável, mas com dificuldades com a própria língua portuguesa (compreensão leitora e expressão escrita).

Os professores brasileiros se queixam de que os estudantes, em sua maioria, não têm as disposições básicas de estudar tais como: tomar notas; organizar seu material; planejar e dedicar tempo às tarefas de estudo; revisar o texto produzido; sublinhar o que se lê; preparar resumos e esquemas conceituais. Muitos sequer dominam os comandos mais elementares dos editores eletrônicos de texto e entregam trabalhos manuscritos, que são fotografados e enviados até por aplicativos de mensagem, como o WhatsApp. Muitos não dispõem de computadores nem de internet de banda larga em suas residências. Além destes desafios, o perfil dos estudantes da UPF (em sua maioria mulheres casadas, com filhos, egressas do Ensino Médio há muitos anos sem estudar e inseridas no mercado de trabalho) oferece uma dificuldade extra: a falta de tempo livre para se dedicar às tarefas acadêmicas.

Outro aspecto desfavorável diz respeito ao peso que a tarefa de orientação de trabalho de graduação tem na carreira acadêmica do professor universitário. Há que se considerar que esta tarefa tem muito pouca influência na progressão da carreira ou na disputa por financiamento em editais públicos, tanto no Brasil quanto na Espanha. Se o número de TCC concluídos pode ter algum valor no Currículo Lattes, as horas dedicadas a cada um deles têm valor inversamente proporcional. Ou seja, quanto menos tempo o professor orientador dedica à orientação de cada TCC, mais tempo reserva para dedicar-se às atividades que mais pontuam como a publicação em periódicos qualificados, por exemplo. Um dos entrevistados chegou a comentar assim a carga de orientar TCC: "com tanta coisa para ler para a minha pesquisa, me desespera ler os trabalhos mal escritos dos alunos... se perde muito tempo com isso".

Há que se considerar, também, aspectos materiais, como espaço próprio e reservado para atender os alunos, computadores, impressora, papel, tinta de impressão e acesso à internet, por exemplo. Tudo isso é bem incipiente neste campus. Há pouco espaço reservado para orientação, poucos computadores, poucas impressoras, falta papel, tinta de impressora, a internet cai constantemente, há quedas de luz, faz calor, os aparelhos de ar condicionado são barulhentos e não estão disponíveis em todas as baias de trabalho dos professores. 


\section{Três professores comprometidos do curso experimental}

Os três professores que apresento nesta seção se destacavam pelo status social que gozavam na comunidade. Todos haviam trabalhado na implantação do curso de pedagogia neste município e foram coordenadores de curso. Um dos aspectos, contudo, que colaborou enormemente para a aquisição deste status foi o fato de terem sido os últimos a "abandonarem o barco" (deixarem de trabalhar com os alunos remanescentes).

Outros docentes, uma vez encerrado o convênio com a prefeitura (que financiava a hospedagem dos professores da UPF nesta localidade de interior), passaram a orientar os alunos de maneira remota; estes três, no entanto, mantiveram seu compromisso de forma presencial. Para isso, enfrentavam uma viagem de três horas de ônibus por uma estrada tortuosa, pagando estadia ou fazendo "bate-volta", perfazendo um total de seis horas de viagem num mesmo dia só para atender os alunos que estavam atrasados com seu TCC. Isto era frequentemente comentado na comunidade acadêmica: "eles são realmente muito comprometidos com o projeto! Pagam do próprio bolso só para não deixar os alunos na mão. Isso é muito lindo de ver”.

\section{Um orientador boa praça}

O orientador-boa-praça reconhece a dificuldade de os estudantes de Pedagogia redigirem um TCC: "primeiro, a gente tem que levar em consideração, e eu levo, eu trato com a maior dignidade e respeito, porque eu sei que são nossos alunos de Pedagogia os mais desprovidos dos que têm acesso à universidade, porque ninguém quer ser professor”. Segundo ele, os estudantes que fazem Pedagogia "das classes de uma elite que chega a fazer vestibular, esses são os mais periféricos [...] isso faz com que eles venham com mais dificuldades do que a média. Tem que aprender a escrever sim”.

Ou seja, ele reconhece que os alunos chegam ao final do curso sem saber algumas operações tidas como essenciais para o desenvolvimento do TCC. Uma de suas estratégias de orientação é começar pela história de vida deles. Sobre sua maneira de atuar como orientador, comenta: "Hummm... eu tenho muita paciência! Então, eu faço o aluno reescrever e muito. Eu gosto disso, de ver o aluno escrever três páginas, me devolver cinco, e ir fazendo... e daqui a pouco tem dez [...]. Eu sou minucioso, sabe, eles vão aprendendo”. Apesar de ser muito dedicado, adverte: "Mas eu não sou pai de aluno!”.

O orientado-boa-praça diz gostar de "ajudar" os estudantes "abandonados", os que vão trocando de um orientador a outro sem conseguir avançar: "não conseguem lidar com a orientação. Então, chega um momento que eles precisam de outro diálogo". Segundo ele, tem gente que precisa de um "empurrão", tem gente que precisa de "porrada". Gosta de sair para beber com os alunos e até de orientar no bar. Só não aceita orientar estudante "vagabundo", que não trabalha. 


\section{Um orientador chato, crica, prolixo}

O orientador-chato-crica-prolixo também reconhece a dificuldade dos estudantes de Pedagogia e diz que "o pessoal tem ojeriza de escrever, o grande medo que a escola cria com essa coisa do registro, do papel [...] a gente de certa forma ia tentando desconstruir isso". Ele também relaciona esta dificuldade ao fator social: "sem querer desqualificar, e aí de certa maneira até é uma questão da própria classe social do pessoal que chega ao magistério". Este é o caso de muitos dos professores do curso de Pedagogia no Brasil e deste em particular: "eu vinha de uma família que o meu pai é analfabeto, não quis ser alfabetizado por mim, porque achava uma tristeza [...]. Minha mãe tinha estudado até a quarta série”. A partir desta conjuntura, o orientador-chato-crica-prolixo tem como motivação de seu trabalho, "ensinar esse pessoal a ser multiplicador, e ser o multiplicador não para aqueles companheiros que estão em sala de aula somente ou com os seus alunos, mas também com os seus grupos mais próximos".

Neste sentido, ele aposta em levar seus alunos e seus familiares a atividades culturais e até se responsabilizar pelos gastos: "e não é aquela questão da gratidão (por parte dos convidados), como se fosse assim, uma caridade. Não é isso. É você possibilitar a entrada do cara ali no centro cultural [...]. Isso toca, isso impressiona. Então, são coisas que você não consegue controlar, e vão nascendo experiências interessantes". O orientador-chato-crica-prolixo orienta seus alunos em grupos de pesquisa e tem o compromisso de ser exigente com a escrita, mas se nota sua preocupação em não constranger os alunos: “é claro que não quero o ar de 'eu vou ser bonzinho', não vou querer me queimar com o aluno, não é isso". Para ele, corrigir o aluno "sem desqualificar", "sem criar uma grande barreira" é uma responsabilidade do orientador: "o orientando quer que a gente faça isso! [...] a minha preocupação é saber como falar [...] mas eu acho que tem que falar, porque se não, perde a função dele (do orientador)". Sobre a qualidade da relação, comenta:

eu acho que fica uma coisa, aquela coisa meio que mestre-discípulo, né? [...], não é relação de pai e filho. Tem orientador que escreve (pelo aluno) [...] você pode ajudar na construção de texto, agora a escrita é dele, poxa, a autoria dele tem que ser mantida. Porque a minha autoria também passa um pouco para ele, mas tem que ser uma coisa dele, porque senão, vai ter a minha cara [...] entendeu?

Embora nossa conversa não tenha tratado diretamente da questão da motivação pelo trabalho de orientar, se nota, nesta entrevista, o seu prazer ao comentar que ajudou a preparar o seu aluno-discípulo para a pós-graduação. Interessante o papel que a pós-graduação tem para este entrevistado cujos pais têm pouca escolaridade. Ele começa a conversa contando do doutorado que fez num país vizinho, anos depois de ingressar na carreira. Também conta com satisfação que, quando disse que não ia mais dar aula no novo curso de Pedagogia, seus alunos redigiram um "testamento" para ele voltar, fazendo elogios e ele acabou voltando para finalizar a orientação com três estudantes. Este retorno foi um passo decisivo na consolidação do status de professor comprometido. 


\section{Uma professora primária que se tornou professora universitária}

A professora-primária-que-se-tornou-professora-universitária dava aula em uma escola no subúrbio de uma megalópole brasileira quando decidiu fazer a faculdade de Pedagogia na sede da UPF. Para conciliar as atividades, tinha uma rotina muito árdua, com horários muito apertados e longas distâncias a percorrer de um ponto a outro da cidade em vários modais de transporte. Sua origem social, as dificuldades que teve que enfrentar e o sonho de se formar influenciaram diretamente a construção de laço com seus orientandos, de mesma origem social e com problemas semelhantes aos que ela teve que superar. Esta professora admite ter especial paciência na medida em que conhece as dificuldades enfrentadas e sentia empatia por seus alunos: "quando não leem, não é porque são vagabundos, mas porque não têm tempo, porque trabalham [...] eu sei, porque passei por isso”.

Apesar de muitos problemas de saúde, com grande dificuldade de locomoção e idade avançada, a docente tinha uma dedicação realmente impressionante e era uma das que concentrava o maior número de orientações. "Adotava” todos os casos difíceis, de alunos repetentes e com pouca disponibilidade para estudar. Para ajudar estes alunos, ela tinha um método: pedia que o aluno trouxesse tudo que tinha produzido de escrita ao longo do curso e ajudava a ordenar para "montar um TCC".

Através de seu relato e observação de sua atuação como orientadora, pode-se inferir que, na relação que construía com seus alunos, praticamente era ela quem trabalhava para eles. A partir da demanda do aluno, ajustava seus horários aos dos orientados, e até fazia as reuniões de orientação fora da universidade, em local mais acessível para os estudantes que trabalhavam no centro da cidade. De alguma forma, a professora-primária-que-se-tornou-professora-universitária se manteve fiel ao ethos de trabalhadora esforçada. Sua maior satisfação parece ser a de cumprir as tarefas que lhe cabem da melhor maneira possível e de ser a professora mais dedicada, capaz de ajudar os estudantes com as maiores dificuldades a terem seu tão almejado diploma de nível superior. Este parece ser o plus que recebe, o sentido que dá à fachada de professora comprometida: atender à demanda dos alunos. Esta foi a última a "largar o barco", atendendo até o final os últimos alunos que ainda precisavam redigir seus TCC para se formar.

\section{Três professores comprometidos do curso do Reuni}

Apesar de esta geração de professores já ter sido concursada para o campus do interior da UPF, a grande maioria não mora no município, preferindo enfrentar os deslocamentos semanais. Um aspecto importante da construção da face de comprometido é morar no município ou, pelo menos, ter uma residência alternativa próxima ao campus, e dedicar pelo menos três dias semanais à universidade. Os menos comprometidos, que não são poucos (talvez a maioria), comparecem um único dia na semana, apenas para dar aula e costumam orientar os alunos por e-mail. Ainda assim, há professores que conseguem manter seu status de comprometido mesmo estando fisicamente menos disponível.

As três professoras apresentadas nesta seção são muito queridas pelos alunos, envolvendo-se com eles em muitos outros projetos extraclasses, como movimentos de greve, luta por residência estudantil, 
campanhas de ajuda financeira, entre outros. Duas delas concentram o maior número de bolsistas de diversas modalidades (programas de extensão, iniciação à docência e monitoria). Uma destas professoras fixou residência no município e matriculou sua filha numa escola pública, o que, na hierarquia de nível de comprometimento a eleva à pontuação máxima. As demais, apesar de não terem se mudado, alugam um apartamento (a "república") e estão no mínimo três vezes por semana no município, com dedicação integral, da manhã até a noite, aos trabalhos na universidade, tendo bastante disponibilidade para atender aos alunos.

Pela própria assiduidade na instituição, dão preferência a realizar as reuniões de orientação presencialmente, o que também é um aspecto que contribui para a construção da face de professor comprometido. Outro índice de comprometimento seria o uso das salas de estudo dos professores que, em toda a instituição, são apenas quatro, divididas entre alguns poucos colegas. Estas três professoras não só frequentam uma destas salas, como instalaram aí seu projeto de pesquisa, com equipamentos adquiridos por agências de fomento. Este tipo de empreendimento também reforça sua face de professor comprometido.

\section{Uma orientadora que pesquisa para o aluno}

A orientadora-que-pesquisa-para-o-aluno também tem origem popular, e fez sua graduação à noite, enquanto trabalhava no setor de serviços. Para ela, uma das grandes dificuldades dos estudantes, além da compreensão leitora e produção escrita, é o planejamento da realização das tarefas no tempo previsto para finalização do TCC, e esta é uma das principais funções que assume como orientadora: "ajudar os estudantes a não se dispersarem no tempo". Como a professora-primária-que-se-tornou-professora-universitária, pegou vários alunos com histórico de mudança de orientador, os "casos difíceis", que chegam "desesperados", porque já ultrapassaram todos os prazos. Segundo sua avaliação, tem menos orientandos do que gostaria e acredita que os que lhe procuram o fazem principalmente pelo tema de seu interesse. Gosta de deixar os alunos livres, mas acaba reconhecendo que isso gera problemas, uma vez que eles têm pouca autonomia.

Sobre o trabalho de orientação, comenta: "me toma um tempão, me esgota. É um desgaste [...] tem hora que eu fico com uma raivinha, mas depois passa", fazendo um gesto de vergonha. Como eles têm dificuldade em fazer levantamento bibliográfico, diz que acaba "pesquisando junto", buscando para indicar as leituras, deixando claro que não deveria fazê-lo.

Quanto à relação de afeto com os orientandos, diz preferir ser mais formal. Perguntada sobre quando considera que a orientação acabou, faz uma longa pausa e, depois de um suspiro diz: "quando agradece, eu sinto que deu. Essa para mim é a conclusão". Então, sucede uma espécie de ritual no qual pode se dar a oferta de algum "presentinho". Diz expressamente que o que busca como orientadora é produzir o desejo no orientando de estudar, de transmitir o princípio da disciplina, do esforço, mas que é um trabalho quase sempre frustrante. Apesar disso, costuma reclamar quando não tem nenhum orientando e acha injusto que alguns tenham tantos. 


\title{
Uma orientadora que trabalha com infância
}

A orientadora-que-trabalha-com-infância é jovem e recém-concursada. Para ela, entre todas as tarefas como professora universitária, considera a de orientar TCC uma das mais difíceis. Acredita que os estudantes a procuram pelo desejo de entender esta fase do desenvolvimento, em geral para compreender sua ligação com a própria infância ou a de seus filhos. Normalmente atende às estudantes de idade mais avançada, que são mães e dispõem de pouco tempo livre para estudar. "É muito forte isso, essa alegria com a aproximação do tema e o desejo de entender que fase é esta da vida”. No entanto, quase sempre fica frustrada com o resultado dos TCC que orienta que, em comparação aos de outros colegas que ela avalia, estão num "nível mais abaixo". Para ajudar estas mulheres a organizarem seu tempo, ela passa uns "para casa" com prazos flexíveis. Apesar de reconhecer essa ajuda como uma das funções do orientador, ao menos para este determinado público, não perde "de vista isso: vai ser necessário que eles tomem pra si essa tarefa”.

Esta docente se sente bastante frustrada em sua carreira de orientadora de TCC: "é muito frustrante você ter um orientando, né? E aí, você espera que ele te procure, você procura e tudo mais e, no final, você precisa reprovar porque a pessoa não deu conta pro que tinha que fazer [...]. Às vezes, com um orientando, uma conversa de meia hora é super produtiva, com outro, em duas horas, você não consegue avançar do ponto onde tá". Ela reconhece que é um ganho pessoal para o estudante, mas para o docente que orienta não há muito retorno além de ter contribuído para a formação do aluno que vai ser professor.

Perguntada sobre o que sente quando finaliza um trabalho de orientação, responde: "esse semestre eu tô especialmente feliz, muito feliz com as duas que tão terminando, porque foram trajetórias muito difíceis, muito conturbadas, marcadas por problemas emocionais, problemas de ordem econômica. E elas tão entregando TCC bacanas, bacanas mesmo". Ela define assim a função do orientador:

\begin{abstract}
é interessante que a gente pense que o orientador precisa ser parceiro. Ele não é o carrasco que cobra o produto, sabe? Acho que a gente tem que encarar isso. É uma produção coletiva, é uma produção em grupo. Você com seus orientandos, é uma produção disso tudo. E tornar a coisa mais alegre, sabe, mais prazerosa [...]. A coisa do desejo... Você tem que ter alguma coisa que te faz levantar, né? De manhã, assim... que seja o desejo de ser o melhor profissional, de fazer o bem para as crianças, né? [...] o desejo é esse, né? Uma escola melhor, de que as crianças estejam mais felizes. Vamos ser feliz também!
\end{abstract}

\section{Uma professora que é pau para toda obra}

A professora-que-é-pau-para-toda-obra também é de origem popular com pais pouco escolarizados. É especialmente dedicada não apenas ao trabalho de orientação, mas a todas as tarefas do curso. É seguramente, entre os docentes, uma das que dedica mais tempo à faculdade. Apesar de sua disponibilidade, não são muitos os estudantes que lhe procuram como orientadora: 
- sendo muito sincera... crítica comigo mesma, eu acho que, assim... eu afasto os alunos mais do que aproximo.

- Por quê?

- Porque a questão da religião é uma questão muito presente pra eles, e não tem nada a ver... é um problema a ser combatido (a religiosidade dos estudantes) [...] a maioria acha que foi Deus quem garantiu (a eles) fazer esse trabalho [...]. Sou uma ateia, né? Eu não vejo Deus nos trabalhos. [...] Então, precisava fazer essa avaliação... por que Deus não ajuda direito logo? Por que não dá iluminação pra eles saberem as regras da ABNT direitinho?

Seu primeiro orientando era um rapaz com enormes dificuldades, inclusive para se expressar oralmente. Sentiu-se culpada de reprová-lo por ele não comparecer aos encontros marcados de orientação. A professora-que-é-pau-para-toda-obra se dispõe a atender os estudantes até por WhatsApp "para facilitar a vida deles”. Alguns têm dificuldade de escrever suas dúvidas e mandam mensagens por áudio. Perguntada sobre o tempo que dedica, se dá conta, de repente, que nunca tinha pensado nisso, que são muitas horas e não declara este tempo no seu relatório anual docente. Esta docente trabalha muito na revisão dos textos dos alunos e diz: "no texto dos meus orientandos, eles têm um pouco da minha correção, sabe? Eu dou um tom também, porque não quero que saia texto cheio de erro". E complementa: “...a minha característica de orientadora, pelo menos comparando com os textos que eu já dei parecer dos meus colegas... eu não mando para o parecerista um texto que eu não tenha dado uma limpada”.

Ela conversa muito com os alunos, escuta seus problemas pessoais, dá conselhos e até ajuda alguns financeiramente. Perguntada sobre o que sente quando o trabalho de orientação termina, responde:

fico contente de ver que eles concluíram, que eles cresceram, que foram capazes. [...] É um prazer de ver que a pessoa tá saindo, que concluiu, que valeu a pena. [...] e porque, muitas vezes, os alunos, na hora que eles falam da escolha do tema, da introdução, é uma coisa que eles têm colocado e eu deixo, acho legal... falar um pouco desse trabalho deles, desse sacrifício, desse sofrimento, sabe? De escolher o tema, de como é que foi, desse processo de, de, de... desafio, deles se desafiarem pra escrever um texto. E acho importante. Eles conseguiram. Poxa, acho 'que legal que eles conseguiram!'

Sobre o tipo de recompensa pelo grande esforço de orientar alunos com tantas dificuldades, a professora-que-é-pau-para-toda-obra comenta: "eu me emociono às vezes. Teve um trabalho... [...] ela citou todos nós, né? Inclusive os professores. No trabalho dela, ela vai dizendo o que ela aprendeu. Achei tão bacana ela ir fazendo referências dos professores que passaram pela vida dela [...]. Dá um prazer muito grande!".

\section{Uma professora considerada pasota da UEP}

A professora-considerada-pasota foi bastante solícita em participar da pesquisa. Ela se encontra entre os três professores da UEP que permitiu que eu observasse suas reuniões de orientação por todo um semestre. No período que acompanhei suas atividades, ela orientava três estudantes, além de ser 
coordenadora de área. Em comparação aos demais professores que eu observei e entrevistei no mesmo período, ela se encontrou com suas estudantes um número menor de vezes.

Próximo ao final do período, me chamou atenção o fato de ela solicitar a cada uma das três alunas que assinasse um documento atestando o número de reuniões de orientação que haviam tido. Apenas uma conseguiu concluir seu TCC, sendo a única a me conceder entrevista. Houve comentários entre os discentes de que a coisa não havia corrido bem, e alguns culpavam a professora-considerada-pasota, enquanto outros comentavam, à boca miúda, que as estudantes não haviam se esforçado. Pelo que pude observar deste caso, de fato, a única de suas orientandas que apresentava progressos, encontro após encontro, foi a estudante empollona (“CDF” seria uma boa tradução).

A professora-considerada-pasota foi entrevistada duas vezes, uma no início do trabalho de campo, e outra ao final. Na primeira ocasião, fez muita questão de dizer o quanto era exigente e exibia, em seu gabinete, o grande número de trabalhos orientados por ela. Entre uma entrevista e outra, durante o período de observação participante, a cada vez que tinha problemas com as estudantes que não apresentavam qualquer progresso de um encontro a outro, me convidava para tomar café e tentava se explicar a fim de salvaguardar a sua face.

Foi através dela que eu tive conhecimento do injusto sistema de contabilização das horas dedicadas a esta tarefa na UEP. Na segunda e última entrevista, ela fez uma cativante defesa de seu suposto pasotismo, alegando tratar-se de uma questão política. Considerava absurda a contabilização de tão poucas horas, pois calculava que, para cada orientando, dedicava no mínimo quinze horas, contando não apenas as das reuniões, mas todo o trabalho de correção das inúmeras versões, bem como da pesquisa bibliográfica. Argumentava, ainda, que se esperaria que, ao final do curso, os estudantes tivessem autonomia.

Segundo seu ponto de vista, não trabalhar mais do que é contabilizado é uma forma de pressionar para que haja mudança no sistema de horas dedicadas à orientação. A professora-considerada-pasota aposta na autonomia do estudante, acreditando, ainda, que para aqueles que não sabem estudar sozinhos a esta altura (na universidade), não é função dela lhes ensinar isso; está sempre muito ocupada com eventos na sua área de atuação e, para ela, a tarefa de orientar é uma atividade "mal paga".

\section{Algumas considerações}

A despeito de a situação de orientação de TCC ser uma espécie de caixa preta, que acontece em geral de forma reservada e, normalmente, sem testemunhas, o material de campo que pudemos analisar até o momento nos dá algumas pistas para entender o que acontece nesta "interação cara a cara" (Goffman, 2011). Interessa-me particularmente compreender que tipo de subjetividade é produzida através desta interação em torno da cultura escrita.

Deslocar o foco para esta microssociologia é uma maneira de perceber que a alteridade entre duas pessoas que se relacionam é a unidade mínima da vida social, "um pequeno sistema social” nas palavras do autor e, por isso mesmo, seu fundamento. Será nesta unidade de socialização que os atores sociais aprenderão como se espera que se comportem, bem como saber interpretar ações de outros ato- 
res sociais e o que podem depreender de seu comportamento e, por conseguinte, como reagir de forma aceitável. Para construir sua sociologia, Goffman utiliza como metáfora os elementos da representação cênica. Assim, segundo ele:

Em presença de outros, o indivíduo geralmente inclui em sua atividade sinais que acentuam e configuram de modo impressionante fatos confirmatórios que, sem isso, poderiam permanecer despercebidos ou obscuros. Pois se a atividade do indivíduo tem de tornar-se significativa para os outros, ele precisa mobilizá-la de modo tal que expresse, durante a interação, o que ele precisa transmitir. De fato, pode-se exigir que o ator não somente expresse suas pretensas qualidades durante a interação, mas também que o faça durante uma fração de segundo na interação (Goffman, 1985:36-37).

No jogo cênico da vida social, a estas "pretensas qualidades", Goffman chamará "fachada":

algo que não está alojado dentro ou sobre seu corpo, mas sim algo localizado difusamente no fluxo de eventos no encontro, e que se torna manifesto apenas quando esses eventos são lidos e interpretados para alcançarmos as avaliações expressas neles (Goffman, 2011:15).

Neste sentido, a sociologia de Goffman me parece uma referência imprescindível para compreender a inter-relação entre orientadores e orientandos, desde os rituais de interação, à construção e defesa da face pessoal. Neste artigo, especificamente, trabalho com a categoria professor comprometido como uma fachada a ser preservada e performatizada pelo docente que atua como orientador em oposição ao estigma de professor pasota. Interessou-me conhecer como os professores comprometidos constroem sua fachada.

A partir de Goffman (2011), podemos pensar a ação de orientar TCC como um jogo no qual cada participante faz a sua aposta (por exemplo: "vou conseguir me formar a tempo de fazer a festa com a minha turma" ou "até o final deste período preciso terminar esta orientação seja como for" ou "quero ganhar a nota máxima no meu TCC para impressionar a banca e entrar no mestrado", ou ainda, "preciso ajudar este aluno que tem uma história tão similar a minha") na qual não há garantias de que cada um possa efetivamente "ganhar a aposta".

Pode ser que haja um resultado favorável ou desfavorável em relação ao que poderia ser considerado, nos termos da sociologia goffmaniana de "prêmio". Neste jogo, importa, segundo o autor, avaliar o "tamanho do prêmio comparado com o da aposta", de forma que "subtrair o valor esperado da quantidade apostada dá uma medida no preço ou do lucro em média para se engajar no jogo (...) Quando não há nem vantagem nem desvantagem, o jogo é considerado justo"(ibid.:144, grifo do autor). Isso parece ser o que os professores considerados pasotas costumam buscar. Ora, sabemos que, no caso aqui em relevo, trata-se, ao contrário, de um jogo injusto, ao menos materialmente, no qual o prêmio do orientador dificilmente paga o preço investido: seu tempo, sua dedicação, trabalhar com ou até trabalhar por.

Além do que dizem, não apenas em suas entrevistas, sobre o seu trabalho, enfatizando sua dedicação, especialmente com os estudantes mais vulneráveis, os professores lançam mão de outras estra- 
tégias para preservar sua fachada de comprometido. Uma delas é a de atender orientandos em espaços públicos, não reservados, o que produz efeitos performáticos especialmente interessantes pois, "na medida em que uma representação ressalta os valores oficiais comuns da sociedade em que se processa, podemos considerá-la, à maneira de Durkheim e Radcliffe-Brown, como uma cerimônia, um rejuvenescimento e reafirmação expressivos dos valores morais da comunidade” (Goffman, 1985: 41).

Desta forma, a construção performática da fachada de professor comprometido acaba por desenvolver uma dimensão idealizada e, portanto, pedagógica como fica claro na citação de Cooley (apud Goffman, 1985: 41): "Se nunca tentássemos parecer um pouco melhores do que somos, como poderíamos melhorar ou 'educar-nos de fora para dentro? '”. O que este ideal de orientação, performatizado por alguns professores orientadores, nos diz sobre a formação de professores neste instituto? Por que, afinal, alguns professores dedicam mais tempo do que deveriam, desde uma perspectiva puramente pragmática, a uma tarefa comumente considerada frustrante e mal paga?

A partir dos casos estudados, é possível compreender que alguns professores se esforçam em performatizar a fachada de professores comprometidos como uma forma de distinção. Haveria em primeiro lugar, talvez, um traço sintomático na estrutura de alguns professores que simplesmente "não podem evitar" trabalhar para conseguir os melhores resultados. Estes professores dizem ser assim em todas as áreas de sua vida. No caso destes seis casos analisados, todos são, de fato, especialmente dedicados à instituição, e não apenas à tarefa de orientar os alunos de TCC. Todos tiveram cargos administrativos e participaram de diversos grupos de trabalho, assumindo muitas responsabilidades institucionais. Com exceção da professora recém-concursada, em início de carreira, nenhum dos demais têm um perfil próximo ao que se poderia chamar de "empreendedores acadêmicos", ou seja, não fazem grandes esforços para manter uma grande produção acadêmica. Nenhum dos seis leciona nos cursos de mestrado e doutorado da universidade, por exemplo.

Para estes professores que, por uma razão ou por outra, não conseguiram se inserir na pós-graduação, a orientação de TCC pode representar a possibilidade de ocupar o papel social de orientador. Muitas vezes, os docentes constroem para si a fachada de professor comprometido como uma forma de ocupar uma posição de prestígio alternativa, já que não conseguem ser muito produtivos academicamente. E esse parece ser o tipo de recompensa que buscam. Esta face produz ganhos bastante concretos. Eles adquirem uma espécie de imunidade política, sendo menos atacados pelos colegas nas usuais disputas departamentais e até desfrutando de certos privilégios institucionais, como, por exemplo, verticalizar o horário (concentrar toda a carga horária em apenas um dia), entre vários outros mais ou menos sutis.

Neste grupo, a metade atuou no "chão da escola”, isto é, na Educação Básica. Esta taxa pode parecer baixa mas, comparativamente com a taxa de todo o corpo docente, está certamente acima da média. Ter atuado como professor das séries iniciais poderia ser um traço relacionado ao conhecido ethos maternal de "professorinha primária", conforme comentários colhidos no próprio campo. O contraexemplo, a professora-considerada-pasota, nunca trabalhou na escola, está muito mais empenhada em sua carreira acadêmica, em participar de congressos, pesquisas interinstitucionais, e em publicar. Tem especial preocupação em atingir o topo da carreira antes de se aposentar e, como deixou muito claro em sua entre- 
vista, a orientação de TCC é uma tarefa que é obrigada a desempenhar, mas que não lhe dá nenhuma satisfação especial e da qual não espera criar nenhum tipo de vínculo mais duradouro e afetivo.

Os professores comprometidos costumam se sentir gratificados quando os estudantes voltam a procurá-los depois de formados, expressam sua gratidão através dos agradecimentos no próprio TCC, ou com presentes e homenagens nas cerimônias de formatura. Alguns relatam seu prazer em receber e-mails carinhosos e a manutenção do vínculo com o orientador como uma referência importante na vida profissional e até emocional do aluno. Ao que parece, este pode ser considerado um prêmio que compensa o preço que pagam.

Há também aqueles que expressam algum desejo de reconhecimento pelo seu trabalho, e se preocupam em fazer o melhor porque "é o meu nome que está lá". Neste sentido, se poderia inferir, pela escuta dos professores, uma preocupação, nos termos de Goffman, de preservar a face de orientador competente perante os pares, uma vez que os TCC são avaliados por colegas e se tornam públicos no repositório da universidade, como informa a professora-que-é-pau-para-toda-obra. Esta é uma preocupação que também está presente nas falas da professora-considerada-pasota, que não permite que nenhum de seus orientandos apresente um TCC que ameace a sua reputação.

Alguns expressam seu compromisso político em "fazer a diferença”, em contribuir, de alguma forma, ainda que modesta, para superação das desigualdades sociais de uma sociedade injusta: "fico muito emocionada de ver uma empregada doméstica, negra, trabalhadora, terminando seu curso, sendo autora de um TCC". Há uma aposta no "trabalho de formiguinha", na multiplicação, em formar estudantes que possam vir a ocupar seu lugar como professor o que, para este grupo, representa um passo decisivo de mobilização social. Esta é a sua recompensa, o prêmio esperado.

Também reconheci, um tipo de dedicação que está relacionada com o começo de carreira. Professores que "chegam com muito gás", como é o caso da orientadora-que-trabalha-com-infância. Entrevistas de professores com mais anos de experiência sugerem que alguns acabam aprendendo a adequar seu tempo de dedicação de tal forma que a responsabilidade de orientar TCC não prejudique sua carreira acadêmica, roubando momentos para investir em sua própria pesquisa. É o caso da professora-considerada-pasota, que parece buscar simplesmente um jogo justo.

Poderíamos arriscar, por exemplo, que o tipo de interação que o orientador-boa-praça procura construir com seus alunos esteja relacionado ao ideal de fomentar desejo no estudante de trabalhar seus próprios saberes, encorajando-o a produzir um trabalho autoral e honesto, apesar de simples. Ele acredita e se satisfaz com a mudança que observa em seus orientandos, com o efeito que gera na maneira de estar no mundo: "eu tinha uma aluna que trabalhava com contação de histórias e ela se transformou numa contadora de história de um outro jeito, que a própria teorização que ela ia fazendo da prática dela, a levou (à mudança)”. Por outro lado, o orientador-chato-crica-prolixo expressa claramente seu prazer em indicar caminhos, levar pela mão, ensinar e ser reconhecido por isso: criar discípulos. Chamou-me atenção, por exemplo, que o estudante que ele menciona em sua entrevista chega a se parecer muito fisicamente com seu mestre, em função da aquisição de seu modo de se vestir e se comportar. Parece que o desejável aqui é uma espécie de mimetismo. 
Tanto a orientadora-que-pesquisa-para-o-aluno como a professora-primária-que-se-tornou-professora-universitária e a professora-que-é-pau-para-toda-obra parecem ser exemplos de docentes para as quais o plus pode ser, paradoxalmente, se deixar explorar, trabalhando sob a demanda do aluno e não ao contrário, admitindo chegar a redigir trechos do TCC para "ajudar o estudante a se formar". Como se seu grau de comprometimento estivesse relacionado justamente com esta perda, ou dádiva generosa e desinteressada de um típico comprometimento pela causa (social).

Em alguns casos do campo, não especificamente os aqui trabalhados, se nota que o prêmio se dá pela possibilidade de reprodução acadêmica. Segundo Peirano (2014: 4-5), "a orientação de um aluno é parte fundamental do processo mais amplo de reprodução, continuidade e expansão". Esta autora compreende que "somos todos elos de uma sequência de gerações, e é por meio da relação que se desenvolve entre orientador e orientando que dois pesquisadores vivem uma relação estreita de cumplicidade teórica, inserindo o estudante em uma linhagem". Peirano está se referindo a estudantes de pós-graduação em antropologia, e de como se tornar um antropólogo, mas reconheço em algumas entrevistas, sobretudo nos entreditos, este desejo de reprodução. Esta atuação se relaciona com a necessidade de acumulação do que Bourdieu (2014) chamou de "capital específico puro" do campo científico, ou seja, o "prestígio que se adquire e repassa quase exclusivamente sobre méritos científicos e de reconhecimento".

Desta motivação, se pode derivar uma outra: o desejo de reprodução daquilo que Bourdieu (2014) nomeou de "capital científico institucional ou político", que está relacionado ao poder institucional ligado à ocupação de posições importantes nas instituições científicas e sua reprodução (poder de nomear e de fazer carreira). Estes professores não estariam necessariamente comprometidos com o desenvolvimento dos estudantes, mas com a ampliação de seu próprio poder no campo. Esse tipo de relação ficou muito evidente na apresentação pública dos TCC na semana acadêmica da UPF, onde os orientadores parecem claramente estar disputando entre si. Os estudantes, nestes casos, desenvolvem em seu TCC apenas uma parte da pesquisa do orientador e, como trabalhadores alienados, não a entendem em sua totalidade.

O tema do paternalismo na situação de interação social entre orientadores e orientandos, ainda que denegada ("não sou pai de ninguém"), aparece com bastante frequência. Pela escuta do clima geral do campo empírico, eu diria que a atitude paternalista está muito presente nos cursos de Pedagogia em geral, tanto na UPF quanto na UEP, ainda que em diferentes graus, e haveria que se aprofundar sobre isso em estudos futuros. Um certo messianismo- político-cristão, reflexo da herança do patrono da educação brasileira, Paulo Freire, pode ser uma hipótese plausível para esta tendência no Brasil.

Entre os dois grupos estudados, noto que os professores do Curso do Reuni têm mais preocupação em evitar esta disposição paternalista, e tornar a relação afastada do âmbito pessoal, embora haja contraexemplos justamente entre os "comprometidos". Uma hipótese seria o fato de os docentes do Curso do Reuni terem ingressado na carreira acadêmica mais jovens e, em sua maioria, diretamente após o doutorado, e estando mais atrelados à lógica produtivista que os pioneiros do Curso Experimental, com algumas exceções. Parece que, a cada geração de professores universitários, a gestão do tempo destinado às tarefas obedece mais à lógica produtivista de poupar-se das atividades que não geram 
produto capitalizável e destinar mais tempo possível às atividades que lhe rendem pontos para facilitar a disputa por financiamento de pesquisa, progressão na carreira e prestígio no campo acadêmico.

Também chama atenção a identificação dos professores da UPF com os alunos por terem origens socioeconômicas próximas, e o prazer de ajudar assim como foi ajudado uma vez, ou simplesmente de oferecer aos estudantes a mesma oportunidade que tiveram e pela qual tiveram que lutar com tanto esforço: a de mobilidade social. Nas entrevistas, o objetivo de preparar professores capazes de fazer um bom trabalho na educação fundamental parece se sobrepor, em sua grande maioria, ao desejo de promover a mobilidade social dos estudantes de pedagogia. A preocupação com a qualidade da atuação docente só é explicitada na entrevista da orientadora-que-trabalha-com-infância.

E eu me pergunto se, paradoxalmente, não seria esse o maior papel social dos cursos de Pedagogia. Digo paradoxal uma vez que, apesar de a fachada de professor comprometido estar relacionada justamente com a causa da superação das desigualdades sociais e pela construção de uma sociedade mais justa, na prática, o que mais se valoriza é a mobilidade social individual e não a melhoria da educação fundamental que poderia significar um arco de ação política bem mais amplo. Estes professores parecem estar mais comprometidos com a superação pessoal de seus estudantes em seguir a carreira acadêmica, por exemplo, mesmo sabendo quem repete os passos do seu mestre vai para longe do "chão da escola".

De modo geral, se consideramos os relatos dos estudantes, se aprende muito com os professores exigentes ${ }^{9}$. Em uma das entrevistas com os estudantes, escutei o seguinte comentário:

foi escrevendo o TCC, com ajuda da minha orientadora, que eu realmente aprendi a estudar, a ler e a escrever. Nas disciplinas, a gente sempre tem um jeito de ir aprovando, sem muito esforço... tem muito trabalho em grupo, avaliação oral... mas ler e escrever mesmo, foi no TCC. Aprendi coisa que nunca tinha aprendido na escola, de como escrever melhor e acho que vou poder passar isso para os alunos.

À primeira vista, chama atenção que seja apenas uma minoria capaz de se dedicar a esta tarefa mas, de acordo com as condições de trabalho, surpreende ainda mais que estes professores se dediquem tanto a este trabalho por uma recompensa aparentemente muito mais pessoal.

Embora reconheça a necessidade de aprofundar a análise dos dados empíricos a partir deste referencial teórico, os dados preliminares me dão indícios de sua fecundidade. Espero, sobretudo, que este trabalho possa contribuir para despertar o interesse sobre a importância do trabalho de orientação para além do cumprimento de um mero trâmite burocrático em busca de um diploma de nível superior. Seria desejável que, deste laço, se produzissem agentes mediadores capazes de causar desejo nos estudantes da Educação Básica a produzir leitura e escrita de forma autônoma.

\section{Andréa Pavão é Doutora em Ciências Humanas (Educação) pela Universida- de Pontifícia Católica do Rio de Janeiro (PUC-Rio) e Professora Associada da Universidade Federal Fluminense (UFF).}

9 De acordo com a observação participante, os professores exigentes são aqueles que "tiram o coro do aluno". Embora todo professor exigente seja também comprometido, nem todo professor comprometido é, necessariamente, exigente. 


\section{REFERÊNCIAS}

Bourdieu, P. (1998). Escritos de Educação. Petrópolis: Vozes.

Bourdieu, P. (1999). Comprender. In La miseria del mundo (pp. 527-543). Buenos Aires: Fondo de Cultura Económica.

Bourdieu, P. (2004). Os usos sociais da ciência: por uma sociologia clínica do campo cientifico. São Paulo: Editora da Unesp.

Foote Whyte, W. (1980). Treinando a observação participante. In A. Z. Guimarães (org.). Desvendando máscaras sociais (pp. 77-86). Rio de Janeiro: Francisco Alves.

Frochtengarten, F. (2009). A entrevista como método: uma conversa com Eduardo Coutinho. Psicologia USP, 20(1), 125-138. https://doi.org/10.1590/S0103-65642009000100008

Geertz, C. (2005). Obras e vidas: o antropólogo como autor. $2^{\mathrm{a}}$ ed. Rio de Janeiro: UFRJ.

Goffman, E. (1980). Estigma: notas sobre a manipulação da identidade deteriorada. Rio de Janeiro: Zahar Editores.

Goffman, E. (1985). A representação do eu na vida cotidiana. Petrópolis: Vozes.

Goffman, E. (2012). Ritual de interação: ensaios sobre o comportamento face a face. $2^{\mathrm{a}}$ ed. Petrópolis: Vozes.

Louzano, P., Rocha, V., Moriconi, G., \& Oliveira, R. (2010). Quem quer ser professor? Atratividade, seleção e formação docente no Brasil. Estudos em Avaliação Educacional, 21(47), 543-568. https://doi.org/10.18222/eae214720102463

Oliveira, R. C. de. (2000). O trabalho do antropólogo. $2^{a}$ ed. Brasília: Paralelo 15; São Paulo: Unesp. Pavão, A. (2007). Cultura escrita na formação de professores: trabalhos monográficos em um Curso Normal Superior. Revista Teias, 12, 197-211.

Pavão, A. (2011). Universidade e setores populares: identidades, motivações, projetos e sociabilidades. In T. Dauster (org.). Antropologia e Educação: um saber de fronteira (pp. 59-86). Rio de Janeiro: Editora Forma \& Ação. 
Pavão, A. (2017). Carreira de usuários da cultura escrita e formação de professores: um ensaio etnográfico. Horizontes Antropológicos, 23(49), 255-285. https://doi.org/10.1590/S010471832017000300010

Pavão, A. (2018). La utilización del registro audiovisual y de la conversación como recursos metodológicos en el trabajo etnográfico: alteridad, corporalidad y transferencia. In $I V$ Congreso Internacional de Antropología da AIBR. España: Granada.

Pavão, A., \& Serrado, R. (2017). Representações sobre a profissão docente através da etnografia de cerimônias de formatura. Relatório final da pesquisa de PIBIC: FAPERJ.

Peirano, M. (2004). A teoria vivida - reflexões sobre a orientação em antropologia. Ilha, 6(1-2), 209218. https://periodicos.ufsc.br/index.php/ilha/article/view/16679

Sant'Anna, A. (1999). Sexo. Rio de Janeiro: 7Letras.

Saramago, J. (2001). Ensaio sobre a cegueira. São Paulo: Companhia das Letras.

Velho, G. (1978). Observando o familiar. In E. de O. Nunes (org.). A aventura sociológica: objetividade, paixão, improviso e método na pesquisa social (pp. 36-46). Rio de Janeiro: Zahar Editores. 


\title{
PROFESSORES COMPROMETIDOS: A INTERAÇÃO SOCIAL NA ORIENTAÇÃO DE TRABALHOS DE CONCLUSÃO DE CURSO
}

Resumo: Neste artigo trabalhamos uma categoria nativa específica de pesquisa mais ampla sobre o papel do laço social entre orientadores e estudantes de graduação no desenvolvimento do Trabalho de Conclusão de Curso. Compreendemos que o manejo da cultura escrita depende de mediação social, e os modos diferenciais de sua apropriação reproduzem relações de poder entre seus usuários. Os professores se ressentem dos baixos níveis de proficiência de leitura e escrita dos estudantes. Compreende-se, entretanto, que o domínio da cultura escrita seja indispensável tanto para sua formação quanto atuação profissional. Como desenvolver essas habilidades na graduação? O desafio de produzir um TCC, sob orientação, parece estratégico. Entretanto, as condições materiais para o desenvolvimento desta empreitada não costumam ser atraentes. Neste ensaio nos detemos no trabalho improvável de certos atores sociais que, resistindo à lógica produtivista, reconhecem as dificuldades dos alunos e se dedicam a esta tarefa pouco valorizada profissionalmente. Estes professores são representados pelo termo nativo comprometidos.

Palavras-chave: cultura escrita; interacionismo simbólico; mediação social; formação docente; processo de ensino-aprendizagem.

\section{THE COMMITTED PROFESSORS: SOCIAL INTERACTION IN THE GUIDANCE OF UNDERGRADUATE DISSERTATION}

\begin{abstract}
This article presents a specific native category of a broader research about the role of the social bond between the tutors and the undergraduate students in the development of their dissertation. We understand that the management of the written culture depends on social mediation, and the differential modes of its appropriation reproduce power relations among its users. The professors resent the low levels of written and reading proficiency of the students. It is understood, however, that the domain of the written culture is indispensable not only for the formation but also for professional performance. How can these skills be developed during undergraduate course? The challenge of producing a dissertation, under guidance, seems strategic. However, the material conditions for the development of this process are not usually attractive. In this essay, our focus is on the unlikely work of certain social actors who, resisting the productivist logic, recognize the difficulties of the students and dedicate themselves to this professionally undervalued task. These professors are represented by the native term committed.
\end{abstract}

Keywords: Written culture; Symbolic interactionism; social mediation; teacher training; teaching-learning process.

RECEBIDO: $31 / 05 / 2020$

ACEITO: $30 / 06 / 2021$ 